* Procurador do estado e mestrando em direito ambiental da escola superior Dom Helder Câmara.

** Mestre e Doutor em Direito. Professor do Programa de Mestrado em Direito da Escola Superior Dom Helder Câmara. Procurador da Fazenda Nacional.

\section{A EFETIVA IMPLANTAÇÃO DAS UNIDADES DE CONSERVAÇÃO \\ AMBIENTAL POR MEIO DA DESAPROPRIAÇÃO}

\author{
THE EFFECTIVE IMPLEMENTATION \\ OF ENVIRONMENTAL-CONSERVATION \\ SITES THROUGH THE USE OF \\ DISPOSSESSION
}

\section{Hebert Alves Coelho* Elcio Nacur Rezende***}

Como citar: COELHO, Hebert Alves; REZENDE, Elcio Nacur. A efetiva implantação das unidades de conversação ambiental por meio da desapropriação. Revista do Direito Público, Londrina, v. 11, n. 2, p.165-195, ago. 2016. DOI: $10.5433 / 1980-511 X .2016 v 11 \mathrm{n} 2 \mathrm{p} 165$. ISSN: $1980-511 X$.

RESUMO: O presente artigo analisa a importância das unidades de conservação ambientais. Demonstra que a simples criação das unidades de conservação não é suficiente para se promover adequadamente a tutela ambiental. É imprescindível uma efetiva implantação das unidades de conservação para uma proteção eficaz do meio ambiente ecologicamente equilibrado, em especial da biodiversidade. Constata-se que a desapropriação das propriedades privadas 
em áreas constituídas como unidades de conservação é um importante instrumento para se concretizar esta efetiva implantação. Buscou-se compreender o problema por meio de raciocínio dedutivo, com vertente metodológica jurídico-teórica, alicerçando-se na análise de doutrinas e artigos relacionados ao tema proposto.

Palavras-chave: Unidades de conservação; Biodiversidade; Desapropriação.

ABSTRACT: This paper analyzes the importance of environmental and conservation sites and shows that their mere creation is not satisfactory in the promotion of environmental protection. The implementation of successful conservation areas are needed in order to have effective environmental protection, as these sites are also known for housing rare biodiversity. Therefore, the expropriation of private property in areas that are constituted as conservation sites is an important instrument because it helps materialize successful implantations. This study uses deductive reasoning as its method and bases its research on doctrines and other research related papers.

Key words: Conservation sites; Biodiversity; Expropriation 


\section{INTRODUÇÃO}

O Brasil é o país com a maior biodiversidade no mundo, ou seja, é onde se localiza a maior variedade de formas de vida no planeta terra. Esta assertiva é sustentada pelo Instituto Chico Mendes - ICMBio (2015), na medida em que o Brasil possui cerca de $13 \%$ de todas as espécies de anfíbios conhecidas no mundo, $9 \%$ dos insetos, $10 \%$ dos mamíferos, $20 \%$ das aves, $19 \%$ das plantas e $21 \%$ dos peixes. Estimase que no território brasileiro existem mais de 1,8 milhões de espécies da fauna e da flora. São mais de 120 mil espécies de invertebrados e aproximadamente 8.930 espécies de vertebrados (711 mamíferos, 1900 aves, 732 répteis, 973 anfíbios, 3.133 peixes continentais e 1.376 peixes marinhos), das quais 1.173 estão listadas como ameaçados de extinção.

Essa enorme biodiversidade no território brasileiro aumenta a responsabilidade do poder público e da sociedade brasileira na promoção de formas eficazes de proteção do meio ambiente. A criação e implantação de unidades de conservação, áreas ambientalmente relevantes, é um dos principais instrumentos de tutela desta vasta biodiversidade. Isto justifica a posição de destaque que o Brasil possui no cenário mundial no que se refere à criação de unidades de conservação.

O Brasil possui $74 \%$ das áreas mundialmente protegidas que foram criadas entre 2003 e $2008\left(703.864 \mathrm{Km}^{2}\right)$. Entre Unidades de Conservação Federais, Estaduais, Municipais e particulares, o Brasil possui cerca de 2.400 Unidades, totalizando 1,4 milhão de $\mathrm{Kms}^{2}$, o que corresponde a 16,7\% da área continental brasileira (VOGEL, 2015, p.75-94).

O ICMBio (2015) informa a existência, somente no âmbito federal, de 32 Áreas de Preservação Permanente, 16 Áreas de 
Relevante Interesse Ecológico, 31 Estações Ecológicas, 65 Florestas Naturais, 3 Monumentos Naturais, 67 Parques Nacionais, 1 Reserva de Desenvolvimento, 30 Reservas Biológicas, 58 Reservas Extrativistas e 7 Refúgios da Vida Silvestres. As áreas somadas somente destas unidades de conservação federais correspondem a quase $10 \%$ de todo o território nacional.

De acordo ainda com o ICMBio (2015), sendo o Brasil signatário da Convenção da Diversidade Biológica, o país assumiu o compromisso de destinar sob a forma de Unidade de Conservação 30\% do bioma da Amazônia e 10\% dos demais biomas (Pampa, Pantanal, Caatinga, Cerrado e Mata Atlântica, além dos ecossistemas Marinhos e Costeiros).

A despeito desse expressivo número de unidades de conservação, a proteção da biodiversidade não tem sido eficaz. "[...] estudos recentes demonstram que a taxa de extinção de espécies vem crescendo a ritmo acelerado e alarmante, não dando qualquer sinal de estabilização" (BENJAMIN, 2009, p. 6).

A simples criação das Unidades de Conservação não acarreta a automática proteção da biodiversidade. Para que as Unidades de Conservação sejam eficazes é necessário, ainda, a concreta implantação das mesmas, com níveis adequados de manejo.

A desapropriação de propriedade particulares onde são criadas Unidades de Conservação de domínio público é um importante instrumento para alcançar essa eficácia, evitando-se a existências de indesejados "parques de papel” (LIMA, 2005, p. 647-653).

$\mathrm{O}$ presente trabalho irá analisar a importância da efetiva implantação das unidades de conservação para a proteção da biodiversidade e a relevância da desapropriação de propriedades privadas como instrumento desta implantação. 


\section{EVOLUÇÃOHISTÓRICADACONCEPÇÃODAPROPRIEDADE PARTICULAR}

A concepção atual do direito de propriedade é fruto de uma longa evolução histórica. A lei das XII tábuas, escritas pelos romanos literalmente em 12 tabletes de madeira em 450 a.c, já contemplava alguns aspectos relativos ao direito de propriedade (BRANDÃO, 2001, p. 478).

Na concepção romana, a propriedade possuía um caráter místico e o proprietário podia usar, gozar e dispor da coisa de forma absoluta, exclusiva, perpétua e ilimitada, bem como o de persegui-la das mãos de quem injustamente o detivesse, embora já se falasse em exercício subordinado às exigências do bem comum (MONTEIRO, 1976, p.78-79).

$\mathrm{Na}$ Magna Carta em 1215, que limitou o poder dos Monarcas na Inglaterra, o direito de propriedade ganha destaque e, igualmente, possui contornos de um direito absoluto. Dispõe o art. 39:

Nenhum homem livre será preso, aprisionado ou privado de uma propriedade, ou tornado fora-da-lei, ou exilado, ou de maneira alguma destruído, nem agiremos contra ele ou mandaremos alguém contra ele, a não ser por julgamento legal dos seus pares, ou pela lei da terra. (COMPARATO, 2008, p. 67).

$\mathrm{Na}$ reação da classe burguesa em face do poder absoluto do rei, cujo marco foi a Revolução Francesa em 1789, entendia-se, da mesma forma, o direito de propriedade como sendo absoluto e ilimitado. A Declaração Universal dos Direitos do Homem e do Cidadão, de 26.08.1789, proclamava a propriedade como sendo "direito inviolável 
e sagrado" e o art.544 do Código Civil Francês de 1804, define o direito de propriedade como " o direito de gozar e dispor das coisas do modo mais absoluta" (BRANDÃO, 2001, p. 479).

A revolução industrial, já no século XIX, foi um importante marco de rompimento com o Estado Liberal e do surgimento do Estado Social de Direito, que preconizava a tutela dos direitos sociais. Diante desta concepção, a propriedade deve, agora, cumprir uma função social.

Surgiu, assim, o Estado Social de Direito, ou Estado do bem-estar (Welfare State). O art.27 da Constituição Mexicana de 1917 estabelece, de forma pioneira, a limitação da propriedade privada pelo interesse público, já com a previsão, inclusive, da realização de desapropriações (HERRERA, 2010, p. 14). Com a Carta Política de Weimar de 1919 "a socialização passa a constituir um elemento essencial da propriedade" (BRANDÃO, 2001, p. 479).

Atualmente, a propriedade permanece como um direito individual, mas deve ser exercido em harmonia com os interesses sociais. A Constituição Brasileira de 1988, embora reconheça a propriedade privada como direito fundamental (art.5 $\left.5^{\circ} \mathrm{XII}\right)$ e princípio da ordem econômica (art.170, II), estabelece que a mesma deve ser limitada em razão de sua conotação social (art.5 ${ }^{\circ}$, XXIII e art.170, III).

A Constituição Federal de 1988 acrescentou ao núcleo conceitual outro elemento, de caráter finalístico, exteriorizado pela função social da propriedade, querendo dizer que os bens não são outorgados aos indivíduos para que eles o utilizem até o extremo das tendências egoísticas e sacrifício geral, mas com sujeição do gozo deles a condicionamentos proveitosos ao maior número" (BRANDÃO, 2001, p. 481). 
O direito de propriedade não é, pois, um direito absoluto. Deve o mesmo cumprir uma função social.

A função social da propriedade constitui verdadeira limitação a esse direito fundamental. O proprietário não pode usar ou deixar de usar a propriedade conforme seus desígnios. Necessário que ela cumpra uma função social, quer seja com caráter de moradia, unidade produtiva ou, simplesmente, de preservação ambiental (CASTRO, 2015, p. 14).

No mesmo sentido, o art.1228 proclama que:

$\S 1^{\circ} \mathrm{O}$ direito de propriedade deve ser exercido em consonância com as suas finalidades econômicas e sociais e de modo que sejam preservados, de conformidade com o estabelecido em lei formal, a flora, a fauna, as belezas naturais, o equilíbrio ecológico e o patrimônio histórico e artístico, bem como evitada a poluição do ar e das águas. (BRASIL..., 2015, p. 228).

Assim, toda e qualquer propriedade deve cumprir sua função social.

A instituição de espaços ambientais especialmente protegidos constitui uma das mais relevantes incumbências do Poder Público na busca da efetividade do princípio da função social da propriedade em sua dimensão ambiental (FIGUEIREDO, 2010, p. 296).

Nas propriedades privadas em que são criadas unidades de 
conservação, em razão de suas características naturais relevantes, essa função social é ainda mais proeminente, a tal ponto de justificar, inclusive, sua desapropriação.

\section{AS UNIDADES DE CONSERVAÇÃO}

\subsection{A ORIGEM HISTÓRICA DAS UNIDADES DE CONSERVAÇÃO}

A ideia inicial da criação de espaços ambientalmente protegidos não foi propriamente a tutela do meio ambiente ou a proteção da biodiversidade.

Procurava-se, tão somente, evitar o esgotamento de recursos naturais que poderiam ser utilizados pelas pessoas. Como o tempo, as unidades de conservação passaram a ter como justificativa a necessidade de se resguardar o direito fundamental do meio ambiente ecologicamente equilibrado e, mais precisamente, a biodiversidade:

Atualmente, os espaços naturais protegidos, como técnica de tutela ambiental, estão presentes na legislação de praticamente todos os países. Já não trazem no elemento religioso ou cultural sua marca dominante, aspirando, agora abertamente, garantir a existência de espécies, ecossistemas, bancos genéticos ou monumentos naturais de rara beleza. (BENJAMIN, 2009, p. 10).

O surgimento do Parque Nacional de Yellowstone, em 1890, nos Estados Unidos, foi um marco na a utilização destes espaços como forma de preservação ambiental (OLIVEIRA, 2010, p.147).

A partir do final do século XIX e início do século XX, com 
exemplo inicial do Parque de Yellowstone, começaram a disseminar o surgimento dessas áreas protegidas de grande beleza e geralmente abertas ao turismo. Foram criadas áreas semelhantes na Nova Zelândia (1894), África do Sul (1898), México (1898) e Argentina (1934) entre outros (LEUZINGER, 2008). Este modelo de parque se consolidou como um padrão mundial, principalmente a partir da década de 1960, quando o número e a extensão das áreas protegidas foram ampliadas enormemente em todo o mundo (ARRUDA, 1999, p. 79-92).

A criação das unidades de conservação é um dos principais instrumentos de conservação da biodiversidade e parte da concepção que é de grande importância manter certos espaços naturais em seu estado original.

\subsection{UNIDADES DE CONSERVAÇÃO NO BRASIL}

O Código Florestal de 1934 (Decreto n.23.793, de 23 de janeiro de 1934) já previa a criação de alguns espaços protegidos: florestas protetoras, florestas remanescentes, florestas modelos, florestas de rendimento e parques nacionais. O primeiro Parque Nacional brasileiro: o Parque Nacional de Itatiaia, foi criado em 1937. Em seguida, em 1939 foi criado o Parque Serra dos Órgãos (FRANCO, 2011). Nada obstante, o escopo ainda não era a conservação da biodiversidade, mas tão somente a regulamentação da utilização de alguns recursos naturais.

Somente com o Código Florestal de 1965 (Lei n. 4.771) é que se iniciou a sistematização das áreas ambientalmente relevantes, prevendose a criação de unidades de conservação de uso indireto (Parques Nacionais e Reservas Biológicas) e de uso direto (Florestas Nacionais, Reservas Florestais e Parques de Caça Florestais). 
Ainda com intuito de sistematizar a criação de unidades de conservação, em 1979, o Instituto Brasileiro de Desenvolvimento Florestal (IBDF), então responsável pela administração da maior parte das unidades de conservação, propôs Plano do Sistema de Unidades de Conservação para o Brasil, tendo, entre seus objetivos, a identificação de áreas com potencial interesse para a proteção (OLIVEIRA, 2010, p.156-157).

Observa-se que a adoção do modelo de áreas protegidas no Brasil, como instrumento de tutela da natureza, é anterior ao surgimento do Direito Ambiental, como disciplina orgânica e autônoma, estruturada em torno de características, objetivos, princípios e instrumentos próprios (BENJAMIN, 2009).

Com o advento da Constituição Federal de 1988, foi prevista a possibilidade do Poder Público criar áreas especialmente protegidas. A proteção dos espaços especialmente protegidos, abrange, além das unidades de conservação, as Áreas de Preservação Permanente e as Reservas Legais. Dispõe o art.225 da CF:

Art. 225. Todos têm direito ao meio ambiente ecologicamente equilibrado, bem de uso comum do povo e essencial à sadia qualidade de vida, impondose ao Poder Público e à coletividade o dever de defendê-lo e preservá-lo para as presentes e futuras gerações.

$\S 1^{\circ}$ Para assegurar a efetividade desse direito, incumbe ao Poder Público:

(...)

III - definir, em todas as unidades da Federação, espaços territoriais e seus componentes a serem especialmente protegidos, sendo a alteração e a supressão permitidas somente através de lei, vedada 
qualquer utilização que comprometa a integridade dos atributos que justifiquem sua proteção. (BRASIL..., 2015, p. 127).

Em seguida, a lei 9.985/2000, conhecida como a Lei do SNUC, regulamentou a Constituição Federal e instituiu o Sistema Nacional de Unidades de Conservação da Natureza, estabelecendo, de forma inovadora, critérios para a criação, implantação e gestão das unidades de conservação. Dispõe o art. $2^{\circ}$ da lei 9.985/00:

Art. $2^{\circ}$ Para os fins previstos nesta Lei, entende-se por:

I - unidade de conservação: espaço territorial

e seus recursos ambientais, incluindo as águas jurisdicionais, com características naturais relevantes, legalmente instituído pelo Poder Público, com objetivos de conservação e limites definidos, sob regime especial de administração, ao qual se aplicam garantias adequadas de proteção.

A referida lei criou 12 categorias de manejo, divididas em 2 grupos:

As Unidades de Proteção Integral, que não admitem utilização direta dos recursos naturais, e as Unidades de Uso Sustentável, que permitem a utilização de forma racional e dentro dos limites previstos, dos recursos ambientais (LEUZINGER, 2008, p. 545).

Além disso, nas Unidades de Proteção Integral a presença humana não é admitida de forma permanente, mas apenas esporádica, com fins turísticos, educativos ou científicos. Já nas Unidades de Uso Sustentável, a tutela ambiental já presume a ocupação humana, ainda 
que baixa ou restrita a certos grupos (OLIVEIRA, 2010, p.149).

As referidas unidades de conservação visam, além da preservação da natureza e da biodiversidade, o estímulo à pesquisas científicas e atividades recreativas, voltadas ao turismo ecológico.

A Declaração de Estocolmo (1972), em seu Princípio 4º já prevê a responsabilidade do homem pelo habitat da flora e da fauna:

Princípios 4 - O homem tem a responsabilidade especial de preservar e administrar judiciosamente o patrimônio da flora e da fauna silvestres e seu habitat, que se encontram atualmente, em grave perigo, devido a uma combinação de fatores adversos. Consequentemente, ao planificar o desenvolvimento econômico deve-se atribuir importância à conservação da natureza, incluídas a flora e a fauna silvestres. (Declaração de Estocolmo, 1972, p.2).

Ainda no âmbito internacional, as áreas objeto de especial proteção ambiental foram objeto de um tratado internacional das Nações Unidas: a Convenção sobre Biodiversidade Biológica (1992).

A referida Convenção estabelecida pela Conferência das Nações Unidas sobre o Meio Ambiente e Desenvolvimento Sustentável realizada no Rio de Janeiro em 1992 foi ratificada pelo Brasil através do Decreto Legislativo $\mathrm{n}^{\mathrm{o}}$ 2, de 1994.

Dispõe o art. $8^{\circ}$ dessa Convenção ser dever da parte contratante: "Estabelecer um sistema de áreas protegidas ou áreas onde medidas especiais precisem ser tomadas para conservar a diversidade biológica”. Nas palavras de Herman Benjamim (2001, p. 3):

Aqueles, popularmente conhecidos como "seres 
vivos", foram, em tempos recentes, rebatizados, passando a constituir a biodiversidade do planeta, um complexo mosaico de genes, espécies e ecossistemas, cuja proteção parece unir povos e culturas em uma unanimidade difícil de encontrar no campo das ideias, quanto mais daquelas recém saídas do forno da ciência.

A fauna e a flora compõem a diversidade biológica e conforme expõe Custódio (2006, p. 402) tem funções genéticas, sociais, medicinais, econômicas, científicas, tecnológicas, alimentares, espirituais, religiosas, educacionais, recreativas, culturais, estético-paisagísticos e turísticos.

A referida Convenção reconhece a importância da diversidade biológica para a evolução e para a manutenção dos sistemas necessários à vida da biosfera e entende como fundamental para a proteção da diversidade biológica a conservação in situ dos ecossistemas e dos habitats naturais, além da manutenção e recuperação de populações viáveis de espécies no seu meio natural.

\subsection{A IMPORTÂNCIA DA CRIAÇÃO DAS UNIDADES DE CONSERVAÇÃO}

As áreas em que são constituídas e efetivamente implantadas as unidades de conservação possuem grande importância para a manutenção do equilíbrio ambiental, em especial pela preservação da biodiversidade, já que se evita a destruição e a degradação do habitat da fauna e da flora. Cumpre ressaltar que: 
[...] os ecossistemas são um reservatório extraordinário e ainda inexplorado de informações bioquímicas e genéticas, capazes, quem sabe, de modificar, para melhor e por inteiro, nosso futuro, com avanços tecnológicos atualmente sequer imaginados. (BENJAMIN, 2009, p. 5)

Percebe-se, assim, a importância que as Unidades de Conservação possuem para as pesquisas científicas e para a conservação da biodiversidade, muitas vezes com a descoberta de plantas endêmicas e novas espécies de animais.

A criação de espaços territoriais especialmente protegidos - ETEP vem sendo apontada por grande parte da comunidade científica como uma das mais eficientes formas de proteção da diversidade biológica in situ, encontrando-se previsão em diversos documentos internacionais, como a Convenção sobre a Diversidade Biológica - CDB. (LEUZINGER, 2008, p. 531).

Além disto, cumpre ressaltar ainda a grande vocação que as referidas áreas possuem relativa ao turismo ecológico. "Há nestas unidades de conservação uma crescente demanda de visitação que ultrapassa 4 milhões de visitantes por ano" (ICMBio, 2015). O ecoturismo contribui, inclusive, para despertar a consciência ecológica, ainda que "depois de uma despretensiosa visita a um parque como o de Itatiaia do Iguaçu ou da Serra do Mar.” (FIGUEIREDO, 2010, p. 292).

A criação de espaços territoriais especialmente protegidos, dentre os quais unidades de conservação, é considerada uma das melhores estratégias para a conservação da biodiversidade in situ (LEUZINGER, 
2008). Sendo um dos mais eficientes instrumentos na preservação da biodiversidade, necessário esclarecer sobre o processo de criação e implantação das Unidades de Conservação.

\subsection{O PROCESSO DE CRIAÇÃO DAS UNIDADES DE CONSERVAÇÃO NO BRASIL.}

Até a década de 60 , a criação de unidades de conservação não obedecia nenhum critério rigoroso (FRANCO, 2011). A lei 9.985/2000 sistematizou o tratamento normativo relativo às unidades de conservação. $O$ art. 22 da lei 9.985/00 prevê além da realização de consulta (reuniões públicas), a realização de estudos técnicos prévios determinando a localização, dimensão e limites e o decreto 4.340/02 densifica este dispositivo legal apontando qual a categoria de manejo deve ser escolhida quando da criação das unidades de conservação (OLIVEIRA, 2010, p.151).

Os estudos técnicos são de primordial importância para determinar a escolha da categoria e dos limites adequados à UC a ser proposta. Via de regra, são realizados levantamentos e elaborados relatórios com foco no meio natural (físico e biótico), socioeconômico, cultural e fundiário, cuja profundidade da análise pode diferir em funções das particularidades de cada proposta ( ....). Conta ainda, como principal marco referencial, com realização de uma ou mais consultas públicas. As consultas públicas são reuniões abertas à sociedade, precedidas de amplo processo de divulgação, nas quais a proposta deve ser apresentada de forma clara e acessível, possibilitando aos cidadãos e instituições locais que manifestem sua posição e considerações sobre a proposta (ICMBio, 2015). 
A lei 9.985/00 dispõe, ainda, que as unidades de conservação são 'legalmente constituídos' pelo poder público. Assim, é necessário ato normativo (lei ou decreto) para a criação das Unidades de Conservação.

Entretanto, para uma efetiva proteção ambiental, não basta a criação das unidades de conservação. A fim de se atingir uma verdadeira efetividade na tutela da biodiversidade é necessário o planejamento da concreta implantação destas unidades de conservação, sob pena de se tornarem "parques de papel", ou seja, áreas que são apenas formalmente unidades de conservação constituídas pelo poder público por ato normativo, mas que, na prática, não contribuem, ou contribuem pouco, para a manutenção do equilíbrio ambiental.

Percebe-se que, não raro, o poder público se preocupa em apenas criar as unidades de conservação, sem, contudo, planejar sua implantação (LIMA, 2005).

Após criada, uma unidade precisa ser consolidada territorialmente, ou seja, é necessário demarcar e sinalizar os seus limites e regularizar sua situação fundiária, considerando condições essenciais para planejamento e execução de sua proteção e gestão (ICMBio, 2015).

A simples criação das Unidades de Conservação por lei ou por decreto, precedidas dos estudos técnicos, não caracteriza a transferência automática da propriedade particular ou atribui automática proteção ambiental à referida área. A fim de se atribuir uma real eficácia à proteção ambiental nestas áreas, quando forem particulares, necessário de faz a realização de desapropriações.

\subsection{A DESAPROPRIAÇÃO NO BRASIL PARA A IMPLANTAÇÃO CONCRETA DAS UNIDADES DE CONSERVAÇÃO}


Não basta a simples criação da unidade de conservação. Para uma real efetividade na tutela ambiental, necessário, ainda, sua concreta implantação. Neste sentido, a regularização fundiária através de desapropriações adquire especial relevância.

Diante da criação das unidades de conservação sobre propriedades particulares, percebe-se um potencial conflito de interesses. O proprietário do imóvel particular, cuja área foi instituída pelo poder público como unidade de conservação, não deixa, por isto, de ser proprietário.

Com fundamento na supremacia do interesse público sobre o privado, através da desapropriação, o ordenamento jurídico brasileiro admite que um bem particular seja compulsoriamente despojado de sua propriedade, que passa a ser pública.

A desapropriação é regulamentada, no Brasil, pelo Decreto-Lei 3.365/41 que foi recepcionado pelo art.5 XXIV Constituição de 1988. $\mathrm{O}$ referido Decreto, vigente a 75 anos, dispõe sobre a desapropriação por utilidade pública.

$\mathrm{O}$ art. $5^{\circ}$ do Decreto-Lei 3.365/41 elenca como sendo utilidade pública para fins de desapropriação os locais particularmente dotados pela natureza. Dispõe o referido dispositivo:

Art. 5o - Consideram-se casos de utilidade pública: k) a preservação e conservação dos monumentos históricos e artísticos, isolados ou integrados em conjuntos urbanos ou rurais, bem como as medidas necessárias a manter-lhes e realçar-lhes os aspectos mais valiosos ou característicos e, ainda, a proteção de paisagens e locais particularmente dotados pela natureza_(BRASIL, 2015, p. 31) (grifo nosso). 
Interessante observar que em uma época em que a preocupação com defesa do meio ambiente ainda não existia ou era insignificante, o Brasil já possuía previsão legislativa, pelo referido decreto de 1941, visando a desapropriação para a proteção de locais com características naturais relevantes. No mesmo sentido, a lei 4.132/1962 estabelece, também, as hipóteses de ocorrência de interesse social para fins de desapropriação, entre elas destaca-se:

Art. $2^{\circ}$ Considera-se de interesse social: VII - a proteção do solo e a preservação de cursos e mananciais de água e de reservas florestais. VIII - a utilização de áreas, locais ou bens que, por suas características, sejam apropriados ao desenvolvimento de atividades turísticas. (Incluído pela Lei no 6.513, de 20.12.77) (BRASIL. 1962, p. 1).

Justifica-se, assim, a desapropriação, por utilidade pública ou interesse social, das propriedades privadas que possuam características naturais relevantes, de forma a se atribuir às mesmas a importante função social relacionada à tutela do meio ambiente ecologicamente equilibrado (art.225 da CF).

\section{DESAPROPRIAÇÃO E UNIDADES DE CONSERVAÇÃO}

Apesar do grande número de unidades de conservação existentes no Brasil, tem-se constatado que a simples existência das mesmas não tem sido eficaz na proteção da biodiversidade. Verifica-se um aumento do ritmo de extinção de diversas espécies, como, ainda, tem sido aferido que, mesmo espécies ainda sem risco imediato de extinção tem apresentado preocupante decréscimo populacional e 
declínio de sua variabilidade genética. Estima-se que, desde 1600, 85 espécies de mamíferos e 113 espécies de pássaros foram extintos em todo o mundo (BENJAMIN, 2009).

O Ministério de Meio Ambiente divulgou recentemente uma nova lista das espécies ameaçadas de extinção, constatando-se que o número de espécies que se encontram nessa situação de risco quase triplicou desde o último levantamento, indicando que a situação de conservação da biodiversidade se encontra deficiente (LIMA, 2005, p.647-653).

Para que essa eficiência seja alcançada, não basta a criação das unidades de conservação, é necessário que as mesmas sejam efetivamente implantadas para se atingir um nível satisfatório de manejo, sob pena de se tornarem "parques de papel".

Segundo Terborgh e Schaik (2002), uma grande fração das unidades de conservação no mundo representa os chamados "parques de papel". Esse termo se refere às unidades de conservação que não foram realmente implantadas e têm apenas uma existência virtual, como linhas desenhadas em mapas oficiais. Cerca de $70 \%$ dos parques tropicais possuem pessoas vivendo em seu interior.

Segundo Schaik e Rijksen (2002) o ato normativo que cria uma unidade de conservação não atribui à mesma automática proteção ambiental e não retira a titularidade do particular da referida área. Embora o parque ou outra área ambientalmente relevante já exista formalmente, a mesma não está, ainda, implantada e, portanto, ainda não tutela efetivamente a biodiversidade.

Deve-se implementar uma sede administrativa, um centro de 
visitantes, centro de pesquisas, trilhas adequadas e sinalizadas, placas educativas, lixeiras, mesas, banheiros, número adequado de funcionários, melhoria nos acessos. Sem uma adequada infraestrutura e gestão, as unidades de conservação não cumprirão adequadamente sua função ambiental. Para que isto ocorra, não basta a simples criação formal das mesmas.

A crescente demanda de visitantes em unidades de conservação faz surgir essa necessidade de implantação de melhor estrutura, inclusive o desenvolvimento de unidades de lazer nestas áreas (TROBIA; MOREIRA, 2014), o que pode não ser conciliável com as atividades econômicas desenvolvidas pelos proprietários privados.

A permanência do imóvel, onde foi criada a unidade de conservação, como sendo de propriedade privada, tende a inviabilizar a efetividade da mesma para o objetivo para a qual a qual foi criada, prejudica o seu adequado gerenciamento e compromete seus objetivos de manejo.

Diante da criação das unidades de conservação em propriedades privadas, tem-se, de um lado, o proprietário, que não deixa de sê-lo, pela simples criação da unidade de Conservação e tem, pois, o direito de exercer seus poderes inerentes ao domínio como o de usar e gozar do imóvel em seu proveito pessoal e, de outro lado, a área, considerada de especial relevância ambiental que deve ser utilizada em atividades de preservação da biodiversidade, pesquisas e visitação pública.

Havendo incompatibilidade entre o direito da coletividade pela efetiva implantação das unidades de conservação e o direito do proprietário no exercício de seus direitos inerentes à propriedade privada, deverá prevalecer o interesse público, manifestado pela função social da propriedade na proteção da biodiversidade (TROBIA; MOREIRA, 
2014). Nestes casos, a desapropriação se faz necessária.

O Parque Nacional dos Campos Gerais possui dezenas de propriedades particulares com atividades econômicas incompatíveis com a categoria de Parque Nacional, tais como criação animal, produção de grãos e silvicultura, além da caça, pesca e a coleta de espécies da fauna e flora que também são observadas na região (TROBIA; MOREIRA, 2014, p. 7).

O proprietário e possuidor do imóvel onde foi criada a área ambientalmente protegida poderá, nos termos do art.1228 do Código Civil, usar, gozar, dispor e reaver sua propriedade de quem quer que injustamente o possua ou detenha. No entanto, a criação e implantação das unidades de conservação poderá impossibilitar que o proprietário particular explore sua área.

Tendo sido atingido em seus poderes inerentes à propriedade, em especial no uso e gozo da mesma, pode o proprietário particular, inclusive, manejar ações possessórias, petitórias e indenizatórias (ação de desapropriação indireta) em face do poder público que instituiu as unidades de conservação para a tutela de suas atividades econômicas desenvolvidas.

Caso o poder público institua alguma unidade de conservação em imóvel particular em área que, por lei, deve ser pública, sem promover sua regularização fundiária através da desapropriação e indenização ao proprietário, estar-se-á configurado uma situação de desapropriação indireta, o que deve ser repudiado. "Quando o poder público afeta o bem particular em caráter irreversível, sem nada pagar ou propor, não desapropria, comete esbulho possessório, ou pratica ato ilícito" 
(SANTOS, 2010, p. 99).

A simples criação de uma unidade de conservação, sem a sua regularização fundiária através da desapropriação, poderá ensejar uma indesejada judicialização, em especial naqueles casos em que ocorrer o esvaziamento econômico da propriedade.

Muitas vezes, as restrições impostas ao uso e gozo em uma unidade de conservação implicarão o completo esvaziamento econômico do direito e, ainda que a função socioambiental atualmente integre o próprio conceito de propriedade, a proteção da biodiversidade não pode representar expropriação vedada pela Constituição Federal de 1988 (arts. 5o, XXII a XXIV, e 184). (OLIVEIRA, 2010).

É importante, pois, haja um adequado planejamento prévio à instituição de uma unidade de conservação ambiental. A simples criação das unidades de conservação sem a sua efetiva implantação deve ser evitada. "Se o Estado, ao criar uma unidade de conservação de domínio público, simplesmente afeta determinado bem privado a uma utilidade pública, sem que haja o regular processamento do procedimento expropriatório, estará agindo ilegalmente, [...]" (LEUZINGER, 2008, p. 172).

A criação das unidades de conservação sem que as mesmas sejam efetivamente implantadas é prejudicial ao proprietário, que pode se ver prejudicado no desenvolvimento de suas atividades econômicas, mas é igualmente prejudicial ao poder público, que é, igualmente, obstado no desenvolvimento de suas atividades de preservação da biodiversidade, pesquisas científicas ou visitações públicas.

O proprietário privado poderá, por exemplo, impedir a entrada de visitantes ou mesmo de funcionários dos órgãos ambientais na unidade de conservação ambiental, caso em que, embora seja a área 
particular uma unidade de conservação, a mesma ainda não cumprirá sua adequada função social, já que ainda não foi efetivamente implantada.

Poderá o proprietário, ainda, cobrar ingressos para a entrada em sua propriedade. "Isso porque a exclusividade, assim como a possibilidade de exploração econômica e de disposição, devem ser garantidas ao titular do domínio e, quando afetadas, geram desapropriação indireta." (MACHADO; ALVES, 2014, p. 228).

Após oito anos de tramitação nas Casas Legislativas, e visando eliminar os riscos da criação de "parques de papel" é que foi aprovado, pelo Congresso nacional a lei 9.985/2000, estipulando um novo sistema de áreas protegidas ou Sistema Nacional de Unidades de Conservação (LIMA, 2005).

Dispõe a lei 9.985/00:

Art. $11 \S 1$ 으 Parque Nacional é de posse e domínio públicos, sendo que as áreas particulares incluídas em seus limites serão desapropriadas, de acordo com o que dispõe a lei.

Art.18 § 1ํ A Reserva Extrativista é de domínio público, com uso concedido às populações extrativistas tradicionais conforme o disposto no art. 23 desta Lei e em regulamentação específica, sendo que as áreas particulares incluídas em seus limites devem ser desapropriadas, de acordo com o que dispõe a lei. (BRASIL, 2000, p. 5).

Embora até existam algumas unidades de conservação, como as Reservas Particulares do Patrimônio Nacional, que possam estar localizadas em propriedades privadas, a maior parte delas devem estar situadas em áreas públicas. É o que ocorre, por exemplo, com os Parques Nacionais e as Reservas Extrativistas que devem ser de domínio público. 
Caso um Parque Nacional ou uma Reserva Extrativista sejam constituídas sobre imóvel privado, as mesmas terão que ser, pois, desapropriadas. Neste sentido, a Instrução Normativa n.02/09 do ICMBio estabelece procedimentos técnicos e administrativos para a indenização de benfeitorias e a desapropriação de imóveis rurais localizados no interior de unidades de conservação federais de posse e domínio público.

Desta forma, de acordo com a lei 9.985/00, em algumas unidades de conservação há expressa incompatibilidade com o regime de propriedade privada, já que são de posse e domínio públicos. Estas áreas devem ser necessariamente áreas públicas.

São necessariamente de domínio público: a Estação Ecológica, a Reserva Biológica, o Parque Nacional, a Floresta Nacional, a Reserva Extrativista, e a Reserva de Fauna. Podem ainda, eventualmente, aceitar a dominialidade privada, ora de forma espontânea, ora pela flexibilização: o Monumento Natural, o Refúgio de Vida Silvestre, a Área de Proteção Ambiental, a Área de Relevante Interesse Ecológico, a Reserva de Desenvolvimento Sustentável. Já no caso da Reserva de Desenvolvimento Sustentável, a regra é a dominialidade pública, aceitando-se, contudo, a propriedade privada de certas "áreas particulares incluídas em seus limites", que necessitam ser desapropriadas na hipótese de incompatibilidade com os fins da Unidade (BENJAMIN, 2009, p. 3). Apenas a Reserva Particular do Patrimônio Natural é de posse e domínio necessariamente privado (art.21 da lei 9.605/98).

Há o reconhecimento, assim, de que grande parte das unidades de conservação não podem ser particulares, já que isto seria incompatível com os objetivos que justificaram sua criação. Devendo tais áreas de conservação ser públicas, caso sejam criadas em propriedades privadas, as mesmas deverão, pois, ser desapropriadas. Somente com 
a desapropriação, se viabiliza sua efetiva implantação.

O Parque Nacional e outras UCs como a Estação Ecológica, a Reserva Biológica, a Floresta Nacional, a Reserva Extrativista e a Reserva da Fauna, mesmo estaduais e municipais, quando possuírem terras de domínio privado, tais unidades demandarão desapropriação como previsto em lei, desde que estas áreas não sejam de propriedade pública. (BENJAMIN, 2009. p. 315).

O objetivo de desapropriar para constituir áreas reservas extrativistas, parques e outras unidades de conservação é, certamente, promover uma maior proteção ambiental destas áreas. O poder público retira certas áreas das mãos dos particulares, mediante justa e prévia indenização em dinheiro, para promover melhor sua preservação em razão de sua relevância ambiental. A desapropriação é fundamental para se garantir a boa gestão das unidades de conservação.

Importante haver uma articulação entre os órgãos técnicos, ambientais e jurídicos procurando minimizar problemas na implantação das unidades de conservação. As políticas públicas devem considerar a situação fundiárias das mesmas, já prevendo o montante de recursos que deverão ser dispendidos para viabilizar a implantação das mesmas (OLIVEIRA, 2010).

É recomendável, inclusive, a efetivação da desapropriação previamente a instituição da unidade de conservação. A prévia desapropriação contribuiria para evitar situações de conflito entre os interesses do proprietário particular e os do órgão gestor da unidade de conservação. Há, inclusive, quem defenda que o decreto de criação de uma unidade de conservação somente deve ser expedido após a regular 
desapropriação, inclusive já com o prévio pagamento das indenizações devidas e a transferência definitiva da propriedade ao poder público (LEUZINGER, 2008, p. 172).

Embora o ordenamento jurídico brasileiro não obrigue a desapropriação prévia à criação da unidade de conservação, é aconselhável que o decreto expropriatório seja anterior ao decreto ou lei instituidora da referida unidade de conservação e que, ao menos, a imissão na posse em favor do expropriante (seja aquela obtida pela desapropriação amigável, seja a obtida, na desapropriação judicial, mediante depósito do valor do imóvel em favor do proprietário particular) já tenha sido deferida:

[...], apesar de ser possível a instituição de unidade de conservação de propriedade pública sem a prévia indenização das áreas privadas abrangidas, é essencial uma programação viável para que essa consolidação dominial ocorra em período razoável (OLIVEIRA, 2010, p. 160).

É certo, assim, que a desapropriação dos imóveis particulares em áreas onde foi, ou será instituída, unidades de conservação é fator importante para a consolidação das referidas áreas como efetivamente protetoras da biodiversidade.

\section{CONSIDERAÇÕES FINAIS}

O art.225 da Constituição Federal estabelece o direito fundamental ao meio ambiente ecologicamente equilibrado. Em um Estado Democrático de Direito, mais do que proclamar direitos, os 
mesmos devem ser efetivamente garantidos. A simples criação de unidades de conservação não é suficiente para efetivamente garantir a proteção ambiental, em especial a tutela da biodiversidade. É necessário implementar efetivamente a proteção em tais áreas através de sua regularização fundiária, com metodologias, planejamentos e monitoramentos adequados, de forma a evitar a degradação e imputar responsabilidade aos que provocarem danos ambientais.

Diante da incompatibilidade entre o uso da unidade de conservação para a preservação da biodiversidade e a utilização econômica do mesmo pelo proprietário particular, deve-se prevalecer o interesse público em sua implantação. Assim, a desapropriação de bens privados contribui para resguardar a tutela do direito difuso ao meio ambiente ecologicamente equilibrado.

Não sendo o Direito de Propriedade, direito absoluto, o mesmo poderá ser limitado a fim de se cumprir adequadamente sua função social.

Diante de sua relevância, após a criação das unidades de conservação pelo poder público, as mesmas deverão ser expropriadas, possibilitando, assim, sua efetiva implantação, o que contribuirá para uma eficaz tutela do meio ambiente ecologicamente equilibrado, em especial com a proteção da biodiversidade. A fim de se evitar conflitos entre os proprietários particulares e o poder público e, dentro de um planejamento eficaz, é importante que se efetive a desapropriação previamente à criação da unidade de conservação.

\section{REFERÊNCIAS}

ARRUDA, Rinaldo. Populações tradicionais e a proteção dos recursos naturais em unidades de conservação. Ambiente \& Sociedade, n. 5, p. 
79-92, 1999.

BENJAMIN, Antonio Herman de Vasconcellos e. O direito do consumidor. BDJur, Brasília, DF, 27 jul. 2009. Disponível em: <http:// bdjur.stj.jus.br//dspace/handle/2011/23171>. Acesso em: 12 mar. 2016.

BRANDÃO, Júlio Cezar Lima. Aspectos jurídicos das florestas de preservação permanente e das reservas legais: proteção ambiental e propriedade. Revista de Direito Ambiental, São Paulo, v.22, p. 114146, 2001.

BRASIL. Constituição Federal de 1988. Vade Mecum. 2.ed. São Paulo: Revista dos Tribunais, 2015.

BRASIL. Lei 4.132, de 10 de setembro de 1962. Define os casos de desapropriação por interesse social e dispõe sobre sua aplicação. Disponível em:

$<$ http://www.planalto.gov.br/ccivil_03/leis/L4132.htm>. Acesso em 06 jul. 2015.

BRASIL. Lei 9.985, de 18 de julho de 2000. Regulamenta o art. 225, § 1으, incisos I, II, III e VII da Constituição Federal, institui o Sistema Nacional de Unidades de Conservação da Natureza e dá outras providências. Disponível em: $<$ http://www.planalto.gov.br/ccivil_03/leis/L9985.htm>. Acesso em: 10 dez. 2015.

BRASIL. Lei 10.406, de 10 de janeiro de 2002. Institui o Código Civil. Vade Mecum. 2.ed. São Paulo: Revista dos Tribunais, 2015.

CASTRO, Clarice Rogério de. Reserva legal: proteção indispensável ou intervenção estatal indevida. 2015. 95 f. Dissertação (Mestrado em Direito) - Escola Superior Dom Helder Câmara, Belo Horizonte, 2015.

COMPARATO, Fábio Konder . A afirmação histórica dos direitos humanos. 6. ed. São Paulo: Saraiva, 2008. 
CUSTÓDIO, Helita Barreira. Responsabilidade civil por danos ao meio ambiente. Campinas : Millenium, 2006.

DECLARAÇÃO de Estocolmo sobre os direitos humanos. 1972. Disponível em: $<$ http://www.direitoshumanos.usp.br/index.php/MeioAmbiente/declaracao-de-estocolmo-sobre-o-ambiente-humano.html $>$. Acesso em: 04 mar. 2016.

FIGUEIREDO, Guilherme José Purvim. A propriedade no direito ambiental. 4.ed. São Paulo. Revista dos Tribunais, 2010.

FRANCO, Loren Dutra. Parque Nacional Lagoa do Peixe: criação e uso público dos parques nacionais e a lei $\mathrm{n}^{\circ} 9.985 / 2000$ que instituiu o Sistema Nacional de Unidades de Conservação. Prismas: Direito, Políticas Públicas e Mundialização, Brasília, v. 7, n. 2, 2011.

HERRERA, Carlos Miguel. Estado, Constituição e Direitos Sociais. In: SOUSA NETO, Cláudio Pereira de e SARMENTO, Daniel (orgs). Direitos sociais: fundamentos, judicialização e direitos sociais em espécie. Rio de Janeiro : Lumen Juris, 2010.

INSTITUTO CHICO MENDES DE CONSERVAÇÃO DA BIODIVERSIDADE. ICMbio Fauna Brasileira. Disponível em: $<\underline{\text { http: } / /}$ www.icmbio.gov.br/portal/biodiversidade/fauna-brasileira.html $>$ Acesso em 30.08.15.

LEUZINGER, Márcia Dieguez. Natureza e cultura: criação de unidades de conservação de proteção integral e domínio público habitadas por populações tradicinais. Revista de Direito Ambiental, São Paulo, v. 13, n. 52, 2008.

LIMA, Gumercindo Souza; RIBEIRO, Guido Assunção; GONÇALVES, Wantuelfer. Avaliação da efetividade de manejo das unidades de conservação de proteção integral em Minas Gerais. Revista Árvore, Viçosa, v. 29, n. 4, p. 647-653, 2005. 
MACHADO, Simone Fernandes; ALVES, Kerley dos Santos. Turismo e meio ambiente: relação de interdependência. Revista Meio Ambiente e Sustentabilidade, Curitiba, v.15, n.3, jan./jun, 2014. p. 219-241. Disponível em: $<$ http://www.grupouninter.com.br/revistameioambiente/ index.php/meioAmbiente/article/view/256>. Acesso em: 07 set. 2015.

MAGNA carta. In: WIKIPÉDIA: a enciclopédia livre. Wikimedia, 2016. Disponível em: $<$ https://pt.wikipedia.org/wiki/Magna_Carta\#Refer. C3.AAncias>. Acesso em: 04 set. 2015.

MONTEIRO, Washington de Barros. Curso de direito civil. 16.ed. rev. e atual. São Paulo: Saraiva, 1976. v.3.

OLIVEIRA, Ludmila Junqueira Duarte. Regularização fundiária das unidades de conservação. Boletim Científico. Escola Superior do Ministério Público da União. Brasília, v. 9. n. 32/33, jan./dez., p. 143176, 2010. Disponível em < file:///C:/Users/emsjovanovich/Downloads/ ESMPU\%20Boletim\%20Cientifico\%2032_33.pdf > . Acesso em 03.09.15.

ORGANIZAÇÃO DAS NAÇÕES UNIDAS, Declaração do Rio sobre Meio Ambiente e Desenvolvimento. Rio de Janeiro, 1992. Disponível em http://www.onu.org.br/rio20/documentos/

ORGANIZAÇÃO DAS NAÇÕES UNIDAS. Conferência das Nações Unidas do Meio Ambiente Humano, 1972. Disponível em: <http:// www.onu.org.br/rio20/documentos/ > Acesso em 15.09.15

SANTOS, Cacilda Lopes dos. Desapropriação e política urbana: uma perspectiva interdisciplinar. Editora Fórum. Belo Horizonte. 2010.

TROBIA, Giuliano; MOREIRA, Jasmine Cardozo. Análise da percepção do visitante do Parque Nacional dos Campos Gerais-PR. Revista UNIFAMMA, Maringá, v. 13, n. 2, 2014. 
VOGEL, Huilquer Francisco et al. Pesquisas em unidades de conservação urbanas no Paraná: conhecimentos raramente divulgados ou aplicados. AMBIÊNCIA, Guarapuava, v. 11, n. 1, p. 75-94, 2015.

Como citar: COELHO, Hebert Alves; REZENDE, Elcio Nacur. A efetiva implantação das unidades de conversação ambiental por meio da desapropriação. Revista do Direito Público, Londrina, v. 11, n. 2, p.165-195, ago. 2016. DOI: 10.5433/1980-511X.2016v11n2p165. ISSN: 1980-511X.

Submetido em 13/10/2015

Aprovado em 20/04/2016 